\title{
Antibiotic Effect on Planktonic and Biofilm-Producing Staphylococci
}

\author{
Hassan A. M. Samaha1,2, Mohamed H. Al-Agamy1,3*, Wafaa E. Soliman4 \\ ${ }^{1}$ Microbiology and Immunology Department, Faculty of Pharmacy (Boys Section), Al-Azhar University, Cairo, Egypt \\ ${ }^{2}$ Departmnt of Pharmacognosy and Medicinal Herbs, College of Clinical Pharmacy, Al-Baha University, Al-Baha, Saudi Arabia \\ ${ }^{3}$ Department of Pharmaceutics, Microbiology Division, College of Pharmacy, King Saud University, Riyadh, Saudi Arabia \\ ${ }^{4}$ Department of Microbiology, Faculty of Pharmacy, Delta University for Science and Technology, Mansoura, Egypt \\ Email: *elagamy71@yahoo.com
}

How to cite this paper: Samaha, H.A.M., Al-Agamy, M.H. and Soliman, W.E. (2017) Antibiotic Effect on Planktonic and Biofilm-Producing Staphylococci. Advances in Microbiology, 7, 498-512. https://doi.org/10.4236/aim.2017.76039

Received: April 26, 2017

Accepted: June 18, 2017

Published: June 21, 2017

Copyright $\odot 2017$ by authors and Scientific Research Publishing Inc. This work is licensed under the Creative Commons Attribution International License (CC BY 4.0).

http://creativecommons.org/licenses/by/4.0/ (c) (i) Open Access

\begin{abstract}
The pathogenic effect of Staphylococci is due to extra-cellular factors and properties such as adherence and biofilm production. The nature of the biofilm and the physiological properties of biofilm-producing bacteria result in an inherent antibiotic resistance and require further investigation. Two hundred and sixty Staphylococcal strains were cultured from 600 clinical specimens obtained from hospitalized patients. Among these, 155 were identified as coagulase-positive (CPS) and 105 as coagulase-negative (CNS) staphylococci. Staphylococcal strains were tested for biofilm production using the tissue culture plate (TCP) method. TCP detection showed that of the 155 CPS, $124(80 \%)$ were biofilm producers, while $63(60 \%)$ of the 105 CNS were biofilm producers. Biofilm-producing strains were scanned by scanning electron microscope (SEM) to confirm biofilm formation, study biofilm production, and examine antibiotic effects on biofilm formation. Disc diffusion method was used to study resistance of planktonic and biofilm-forming cells to antibiotics. Planktonic cells were less resistant to antibiotics than biofilm-forming cells. Microbroth dilution method and a new BioTimer assay were used to determine antibiotic MICs affecting planktonic and biofilm cells. Both methods showed that the MICs for planktonic cells were less than that for biofilm cells. The BioTimer assay was therefore found to be sensitive, accurate, and reliable, with results in agreement with those from the broth dilution method and SEM.
\end{abstract}

\section{Keywords}

Staphylococci, Adherence, Biofilm, Tissue Culture Plate, BioTimer Assay Method

\section{Introduction}

The major causes of nosocomial and community-acquired infections and re- 
present a significant burden on the healthcare system are Staphylococcal species. Staphylococcus aureus attachment to medical implants and host tissue, and subsequent establishment of a mature biofilm, play an important role in the persistence of chronic infections [1]. According to the United States National Institutes of Health, more than $60 \%$ of all microbial infections are caused by biofilms [2]. Biofilms are an important microbial virulence factor associated with Staphylococci [3] [4]. Microbial biofilms are sessile microorganisms formed by cells that are attached to and embedded in a hydrated matrix of extracellular polymeric substances, where they grow as organized multicellular communities [5] [6] [7]. Bacteria prefer to live in biofilms for better survival. Growth within a biofilm can thwart immune function and antibiotic therapy and thereby complicate the treatment of infectious diseases, especially chronic and foreign device-associated infections [8]. Biofilm structural properties, as well as the physiological attributes of biofilm-forming organisms, lead to an inherent resistance to antibiotics by delaying the penetration of the biofilm matrix [9]. This increased antibiotic resistance holds serious consequences for infection control, treatment regimes, and disease progression. Biofilms can form on medical implants leading to increased morbidity and mortality of affected individuals [10]. Indeed, biofilm formation is a hallmark characteristic of infections caused by $S$. aureus and $S$. epidermidis, which consist of multiple bacterial layers encased within an exo-polysaccharide glycocalyx [11]. Some substances, including silver nanoparticles, have been used to decrease biofilm formation [12]. These nanoparticles have a higher capacity to attach to and penetrate bacterial membranes and accumulate inside cells, providing a continuous release of silver ions inside the cell, thereby preventing biofilm formation [13].

This study aimed to look into the capability to form biofilm and antimicrobial resistance of 260 clinical isolates of COPS $(n=155)$ and CONS $(n=105)$.

\section{Materials and Methods}

\subsection{Bacterial Isolates}

In the present study, 260 clinical isolates of Staphylococci were recovered from 600 different clinical samples from patients attending Egyptian hospitals. The isolates were collected between January and April 2016. The staphylococcal species were isolated from different clinical infections including Prosthetic joint infection $(\mathrm{n}=55)$, Folliculitis $(\mathrm{n}=47)$, Carbuncle $(\mathrm{n}=41)$, Abscesses $(\mathrm{n}=35)$, Endocarditis $(n=34)$, Urine $(n=27)$, and Sputum $(n=21)$. The isolation and identification of these isolates were carried out in accordance with previously established methodologies [14], and the API system [15]. API Staph strips utilizes a series of 10 biochemical tests, including alkaline phosphatase, urease, $\beta$-glucosidase, $\beta$-glucuronidase, and $\beta$-galactosidase activity, aerobic acid formation from mannose, mannitol, trehalose, and salicin, and utilization of arginine. The strip was inoculated with bacterial suspension which removed from an overnight culture inoculated on Trypticase soy agar plates containing $5 \%$ sheep blood. Reactions of cultures were determined after $5 \mathrm{~h}$ of incubation at $35^{\circ} \mathrm{C}$. 
The color of the strips would then change spontaneously or upon the addition of other reagents. These changes were recorded and interpreted using a reading table and by referring to the Analytical Profile Index.

\subsection{Tissue Culture Plate Method for Biofilm Formation}

The tissue culture plate (TCP) quantitative assay is widely used and considered as the standard for biofilm formation detection. As previously described by Christensen et al. [16], we used 96 flat-bottom-well tissue culture plates, filling each well with $0.2 \mathrm{ml}$ bacterial suspension $(105 \mathrm{CFU} / \mathrm{ml})$ in TSB. After $48 \mathrm{~h}$ incubation at $37^{\circ} \mathrm{C}$, the contents were aspirated and the plates were washed twice with phosphate buffered saline (PBS; pH 7.2). The wells were stained with $0.25 \%$ crystal violet for $30 \mathrm{~s}$ and then the plates were read in an enzyme-linked immunosorbent assay (ELISA) reader (BioTek, ELx808) at $490 \mathrm{~nm}$. Sterile TSB was used as a negative control. Optical density values were then averaged. A 3-grade scale was used to evaluate slime producing ability of each strain: $(-)$, OD < $0.500 ;(+)$, OD $0.500-1.500 ;(++)$, OD $>1.500$. The interpretation of biofilm production as strong, moderate and weak/none was done according to the criteria of Stepanovic et al. [17].

\subsection{Scanning Electron Microscopy (SEM)}

Pure colonies of suspected strains were added to $2.5 \%(\mathrm{v} / \mathrm{v})$ glutaraldehyde in PBS (pH 7.2) for $1.5 \mathrm{~h}$, rinsed with PBS, and then dehydrated in a series of alcohol/water solutions: 30\%, $15 \mathrm{~min}$; 50\%, $15 \mathrm{~min}$; 70\%, $30 \mathrm{~min}$; 90\%, $60 \mathrm{~min}$. Samples were dried and gold-palladium coated. SEM examinations were made using a JSM-840 SEM.

\subsubsection{Antibiotic Sensitivity Test}

Antimicrobial sensitivity tests of the isolated strains were carried out by the disk diffusion method using Mueller-Hinton agar plates. Test strains were pre-inoculated in trypticase soy broth at $37^{\circ} \mathrm{C}$. This suspension was then used to inoculate Mueller-Hinton agar plates by swabbing them with a sterile cotton swab. Antimicrobial discs were placed into and gently pressed down on the surface of the agar plates. Plates were then incubated aerobically for $18-24 \mathrm{~h}$ at $37^{\circ} \mathrm{C}$, following which zones of inhibition were measured and recorded. The results were interpreted as sensitive, intermediate, and resistant according to the Clinical and Laboratory Standards Institute (CLSI) guidelines [18]. Twenty antibiotics were selected to represent different classes and mechanisms of action (gentamicin, amikacin, doxycycline, erythromycin, azithromycin; cephradine, cefotaxime, ceftazdime, cefuroxime, amoxicillin/clavulanic, oxacillin, methicillin, imipenem, vancomycin, ciprofloxacin, levofloxacin, rifampicin, trimethoprim, and novobiocin). Antibiotic solutions were prepared as $100 \mathrm{mM}$ stocks in sterile distilled water.

\subsubsection{MIC Determination}

MICs were determined using the two-fold dilution method in accordance to the 
CLSI guidelines [18]. Different antibiotic concentrations were prepared (from 1 $\mathrm{mg}$ to $0.5 \mu \mathrm{g}$ ). On TSB, a concentration of $10^{6} \mathrm{CFU} / \mathrm{mL}$ was used as the starting inoculation. MIC testing was carried out in flat-bottomed microtitre plates (Greiner, Wemmel, Belgium) and visually evaluated after $24 \mathrm{~h}$ incubation at $37^{\circ} \mathrm{C}$. MIC values were recorded after transferring $100 \mathrm{UL}$ from each clear well of the microtitre plate to a tryptic soy agar (Lab M, International Medical) plate followed by $24 \mathrm{~h}$ incubation at $37^{\circ} \mathrm{C}$.

\subsubsection{Biofilm Growth and Antibiotic Testing}

Staphylococci were prepared and diluted in TSB to a starting concentration of $10^{6} \mathrm{CFU} / \mathrm{ml}$. Bacterial suspensions (100 UL) were added to 96-well plates. Noninoculated TSB was included as a blank. Staphylococcal plates were incubated for $72 \mathrm{~h}$ at $37^{\circ} \mathrm{C}$ on a horizontal shaking plate with growth medium changed every $24 \mathrm{~h}$. Mature Staphylococcus biofilms were obtained after $72 \mathrm{~h}$ incubation at $37^{\circ} \mathrm{C}$. Prior to adding antibiotics, growth medium was discarded and biofilms were washed twice with PBS. Next, $100 \mu \mathrm{L}$ of each antibiotic concentration and $100 \mu \mathrm{L}$ of TSB/well were added to the biofilm plates. Un-treated biofilms (100\% reference values) were obtained by adding $100 \mu \mathrm{L}$ of sterile water instead of antibiotic. The plates were subsequently incubated at $37^{\circ} \mathrm{C}$ for $24 \mathrm{~h}$ on a horizontal shaking plate.

\subsection{MIC Determination by the BioTimer Assay Method (BTA)}

The BTA method [19] uses BioTimer medium with Phenol Red (BT-PR medium) composed of Mueller Hinton broth (21 g), glucose (10 g), phenol red (25 $\mathrm{mg}$ ), and distilled water to $1000 \mathrm{ml}$. After sterilization at $121^{\circ} \mathrm{C}$ for $15 \mathrm{~min}$, the $\mathrm{pH}$ was adjusted to $7.2 \pm 0.1$. BTA measures microbial metabolism: the time required for colour switch of phenol red indicator in BT-PR medium (red-to-yellow) due to Staphylococcus metabolism, is correlated to initial bacterial concentration. Therefore, the time required for colour switch determines the number of bacteria present in a sample at Time 0 through a correlation line. To draw the correlation line specific for Staphylococcus spp., $0.2 \mathrm{ml}$ of MH-overnight broth cultures were mixed with $1.8 \mathrm{ml}$ of BT-PR medium. Serial two-fold dilutions in 1 $\mathrm{ml}$ of BT-PR medium were performed in microtiter plates and simulta neously counted using colony forming unit (CFU) method. Incubation was performed at $37^{\circ} \mathrm{C}$. The colour of the inoculated BT-PR medium was checked at regular time intervals. For each two-fold dilution, the time required for colour switch of BTPR medium was recorded and plotted versus the log 10 of CFUs.

\subsection{Planktonic Form}

Antibiotic sensitivity tests on planktonic forms were performed by the broth dilution method in Mueller Hinton broth according to CLSI, 2015 [18] and in BTPR medium broth according to the BTA method. A total of $10^{5} \mathrm{CFU} / \mathrm{ml}$ from overnight broth cultures were used to inoculate each antibiotic dilution in $1 \mathrm{ml}$ $\mathrm{MH}$ or BT-PR media. After overnight incubation at $37^{\circ} \mathrm{C}$, MICs were deter- 
mined as the lowest antibiotic concentrations that inhibit bacterial growth or BT-PR medium color change.

\subsection{Biofilm Form}

The antibiotic sensitivity of Staphylococci biofilms was evaluated using the BTA method. Staphylococci strains were grown in the presence of sterile glass beads as described above. After incubation at $37^{\circ} \mathrm{C}$, colonized glass beads were washed three times in sterile saline solution. Antibiotic dilutions were prepared in $1 \mathrm{ml}$ of BT-PR medium in 24-well plates. Each antibiotic dilution was inoculated with one colonized glass bead. As controls, two wells containing BT-PR medium without antibiotics were inoculated, with one colonized (Control A) and one containing only a sterile glass bead (Control B). After overnight incubation at $37^{\circ} \mathrm{C}$, the minimal biofilm inhibitory concentrations (MBICs) were determined as the lowest antibiotic concentration that inhibited a color switch of the inoculated BT-PR medium. To determine the minimal biofilm eradication concentrations (MBECs), glass beads from antibiotic dilutions that did not show a color switch were transferred to BT-PR medium without antibiotics. After incubating for $18-24 \mathrm{~h}$ at $37^{\circ} \mathrm{C}$, the wells containing unchanged BT-PR medium corresponding to the lowest antibiotic dilution represented the MBEC values.

\section{Results}

\subsection{Identification of Isolated Strains}

A total of 260 Staphylococcal strains were isolated from 600 different clinical specimens. Of these, 155 were COPS and 105 were CONS. From these, 124 (80\%) and 63 (60\%) were biofilm-producing strains, respectively (Table 1).

Biofilm-producing Staphylococci strains determined by the TCP method as COPS were classified as strong $(80,51.6 \%)$, moderate, $(42,27.1 \%)$, or weak/nonbiofilm $(33,21.3 \%)$. Those determined to be CONS were also classified as strong (50, 47.6\%), moderate $(34,32.4 \%)$, and weak/non-biofilm (21, 20\%, Table 2).

\subsection{Scanning Electron Microscopy Results}

Biofilm-forming strains determined by the TCP method (Figure 1) were imaged using an SEM, which confirmed that all biofilm-forming strains identified by

Table 1. Coagulase-positive and coagulase-negative Staph biofilm formation using the tissue culture plate method (TCP).

\begin{tabular}{cccc}
\hline & $\begin{array}{c}\text { Number of } \\
\text { strains }\end{array}$ & $\begin{array}{c}\text { Number of strains } \\
\text { producing biofilm }\end{array}$ & Percentage \\
\hline $\begin{array}{c}\text { Coagulase-positive } \\
\text { Staph (COPS) }\end{array}$ & 155 & 124 & $60(124 / 155)$ \\
$\begin{array}{c}\text { Coagulase-negative } \\
\text { Staph (CONS) } \\
\text { Total strains }\end{array}$ & 105 & 63 & $603 / 105)$ \\
\hline
\end{tabular}


Table 2. Tissue culture plate method classification of biofilm-forming staphylococci.

\begin{tabular}{ccc}
\hline & COPS (Number $=155)$ & CONS (Number $=105)$ \\
\hline Strong biofilm & $80(51.6 \%)$ & $50(47.6 \%)$ \\
Moderate biofilm & $42(27.1 \%)$ & $34(32.4 \%)$ \\
Weak (non-biofilm) & $33(21.3 \%)$ & $21(20 \%)$ \\
\hline
\end{tabular}

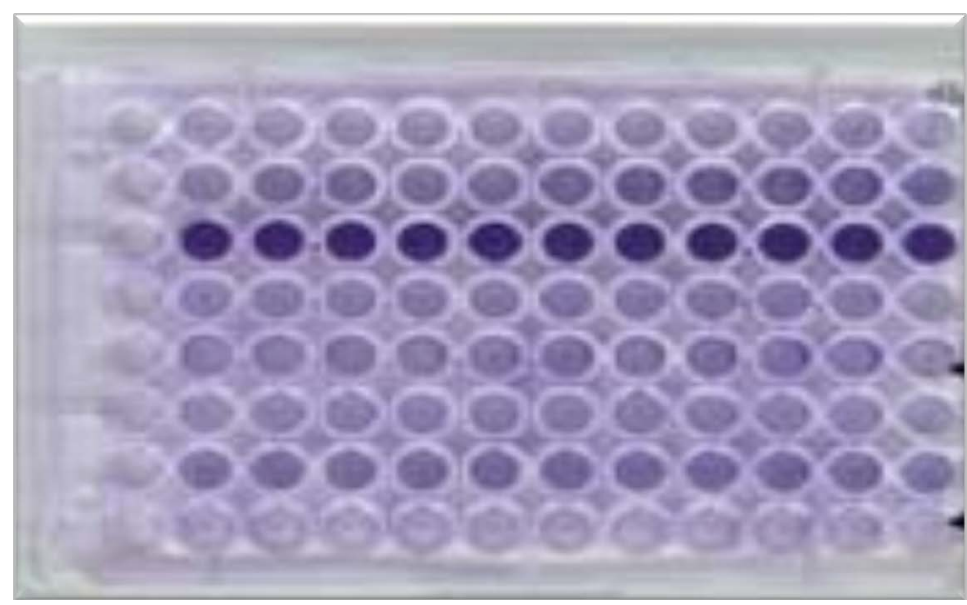

Figure 1. Biofilm formation by tissue culture plate (TCP) method.

TCP did produce biofilm (Figure 2(a), Figure 2(b) and Figure 3(a), Figure $3(\mathrm{~b}))$. Overnight incubation with ciprofloxacin $(128 \mu \mathrm{g} / \mathrm{ml})$ led to reductions in biofilm formation, as indicated by cell detachment or sloughing (Figure 4(a) and Figure 4(b)).

\subsection{Sensitivity Test by Disc Diffusion Method}

Table 3 and Table 4 show that biofilm-forming strains were more resistant to antibiotics than non-biofilm-forming bacteria were.

\subsection{MICs for COPS Planktonic and Biofilm-Producing Cells via the Microbroth Dilution Method}

For planktonic strains, imipenem (IMP) showed the greatest effect; causing a complete reduction of all strains at a concentration of $32 \mu \mathrm{g} / \mathrm{ml}$. However, AMC, CXT, and CIP caused a complete reduction at a concentration of $128 \mu \mathrm{g} / \mathrm{ml}$, while VA caused a complete reduction at a concentration of $512 \mu \mathrm{g} / \mathrm{ml}$, and GN at $1024 \mu \mathrm{g} / \mathrm{ml}$.

For biofilm-producing strains, at a concentration of $512 \mu \mathrm{g} / \mathrm{ml}$, IMP showed the highest effect, causing reduction in $97.5 \%$ of strains (119/122). Ciprofloxacin caused reduction in $95.1 \%$ of strains $(116 / 122)$ at the same concentration. CXT, AMC, VA, and GN caused reductions in 93.4\% (114/122), 90.9\% (111/122), $86.8 \%(106 / 122)$, and $76.2 \%$ (93/122) of strains, respectively (Figure 5, Figure 6) (Table 5).

Table 5 and Table 6 show that MICs (as determined using the microbroth dilution method) for cells where a biofilm was present were higher than that for 
Table 3. COPS antimicrobial sensitivity.

\begin{tabular}{ccccc}
\hline \multirow{2}{*}{ Antibiotic } & \multicolumn{2}{c}{$\begin{array}{c}\text { 122 biofilm-producing strains } \\
\text { nesistant strains } \\
(\%)^{* *}\end{array}$} & $\begin{array}{c}\text { Sensitive strains } \\
(\%)^{*}\end{array}$ & $\begin{array}{c}\text { Resistant strains } \\
(\%)^{* *}\end{array}$ \\
\cline { 2 - 5 } CIP & $76(62.3)$ & $46(37.7)$ & $30(90.9)$ & $3(9.1)$ \\
LEV & $61(50)$ & $61(50)$ & $26(78.7)$ & $7(21.3)$ \\
GN & $28(22.9)$ & $94(77.1)$ & $11(33.3)$ & $22(66.7)$ \\
RF & $33(27.1)$ & $89(72.9)$ & $19(57.5)$ & $14(42.5)$ \\
AZM & $56(45.9)$ & $66(54.1)$ & $24(72.7)$ & $9(27.3)$ \\
DO & $30(24.5)$ & $92(75.5)$ & $18(54.5)$ & $15(45.5)$ \\
VA & $58(47.5)$ & $64(52.5)$ & $21(63.6)$ & $12(36.3)$ \\
ME & $46(37.7)$ & $76(62.3)$ & $18(54.5)$ & $15(45.5)$ \\
AMC & $78(63.9)$ & $44(36.1)$ & $25(75.7)$ & $8(24.3)$ \\
CTX & $62(50.8)$ & $60(49.2)$ & $27(81.8)$ & $6(18.2)$ \\
CRO & $57(46.7)$ & $65(53.3)$ & $25(75.7)$ & $8(24.3)$ \\
IMP & $81(66.3)$ & $41(33.7)$ & $31(93.9)$ & $2(6.1)$ \\
\hline
\end{tabular}

${ }^{*}$ Correlation between the number of sensitive strains to the number of biofilm-forming strains. ${ }^{*}$ Correlation between the number of resistant strains to the number of non-biofilm forming strains. Ciprofloxacin (CIP), Levofloxacin (LEV), Gentamicin (GN), Rifampicin (RF), Azithromycin (AZM), Doxycycline (DO), Vancomycin (VA), Methicillin (ME), Amoxicillin/clavulanic acid (AMC), Cefotaxime (CXT), Ceftriaxone (CRO), Imipenem (IMP).

Table 4. CONS antimicrobial sensitivity.

\begin{tabular}{ccccc}
\hline \multirow{2}{*}{ Antibiotic } & \multicolumn{2}{c}{84 biofilm forming strains } & \multicolumn{2}{c}{21 non-biofilm forming strains } \\
\cline { 2 - 5 } & $\begin{array}{c}\text { Sensitive strains } \\
(\%)^{*}\end{array}$ & $\begin{array}{c}\text { Resistant strains } \\
(\%)^{* *}\end{array}$ & $\begin{array}{c}\text { Sensitive strains } \\
(\%)^{*}\end{array}$ & $\begin{array}{c}\text { Resistant strains } \\
(\%)^{* *}\end{array}$ \\
\hline CIP & $68(81)$ & $16(19)$ & $20(95.3)$ & $1(4.7)$ \\
LEV & $64(76.2)$ & $20(23.8)$ & $19(90.5)$ & $2(9.5)$ \\
GN & $14(16.6)$ & $70(83.4)$ & $10(47.7)$ & $11(52.3)$ \\
RF & $21(25)$ & $63(75)$ & $13(61.9)$ & $8(38.1)$ \\
AZM & $62(73.8)$ & $22(26.2)$ & $15(71.4)$ & $6(28.6)$ \\
DO & $57(67.8)$ & $27(32.2)$ & $14(66.6)$ & $7(33.4)$ \\
VA & $60(71.4)$ & $24(28.6)$ & $16(76.1)$ & $5(23.9)$ \\
ME & $47(56)$ & $37(44)$ & $15(71.4)$ & $6(28.6)$ \\
AMC & $60(71.4)$ & $24(28.6)$ & $17(80.9)$ & $4(19.1)$ \\
CTX & $57(67.8)$ & $27(32.2)$ & $18(85.7)$ & $3(14.3)$ \\
CRO & $54(64.3)$ & $30(35.7)$ & $16(76.1)$ & $5(23.9)$ \\
IMP & $71(84.5)$ & $13(15.5)$ & $20(95.2)$ & $1(4.8)$ \\
\hline
\end{tabular}

${ }^{*}$ Correlation between the number of sensitive strains to the number of biofilm-forming strains. ${ }^{*}$ Correlation between the number of resistant strains to the number of non-biofilm forming strains. Ciprofloxacin (CIP), Levofloxacin (LEV), Gentamicin (GN), Rifampicin (RF), Azithromycin (AZM), Doxacycline (DO), Vancomycin (VA), Methicillin (ME), Amoxicillin/clavulanic acid (AMC), Cefotaxime (CXT), Ceftriaxone (CRO), Imipenem (IMP).

planktonic cells. This indicates that the concentration required for a given antibiotic to completely eradicate biofilm strains was much higher than that required 
Table 5. MICs for COPS planktonic and biofilm-forming cells by the microbroth dilution method.

\begin{tabular}{|c|c|c|c|c|c|c|c|c|c|c|c|c|}
\hline \multirow{2}{*}{$\begin{array}{l}\text { Antibiotic } \\
\text { conc/ml }\end{array}$} & \multicolumn{6}{|c|}{ Planktonic strains $($ total $=122)$} & \multicolumn{6}{|c|}{ Biofilm strains $($ total $=122)$} \\
\hline & AMC & CXT & GN & IMP & VA & CIP & $\mathrm{AMC}$ & CXT & GN & IMP & VA & CIP \\
\hline $1024 \mu \mathrm{g}$ & & & 1 & & & & 11 & 8 & 29 & 3 & 16 & 6 \\
\hline $512 \mu \mathrm{g}$ & & & 4 & & 2 & & 29 & 18 & 38 & 13 & 34 & 25 \\
\hline $256 \mu \mathrm{g}$ & & & 3 & & 5 & & 24 & 26 & 45 & 22 & 26 & 23 \\
\hline $128 \mu \mathrm{g}$ & 1 & 4 & 6 & & 11 & 5 & 32 & 32 & 10 & 30 & 21 & 31 \\
\hline $64 \mu \mathrm{g}$ & 6 & 27 & 33 & & 30 & 35 & 23 & 25 & & 26 & 20 & 18 \\
\hline $32 \mu \mathrm{g}$ & 17 & 21 & 26 & 2 & 28 & 22 & 3 & 12 & & 16 & 5 & 12 \\
\hline $16 \mu \mathrm{g}$ & 34 & 19 & 30 & 9 & 23 & 13 & & 1 & & 10 & & 7 \\
\hline $8 \mu \mathrm{g}$ & 25 & 33 & 9 & 44 & 10 & 15 & & & & 2 & & \\
\hline $4 \mu \mathrm{g}$ & 20 & 11 & 8 & 31 & 6 & 12 & & & & & & \\
\hline $2 \mu \mathrm{g}$ & 14 & 4 & 2 & 27 & 4 & 14 & & & & & & \\
\hline $1 \mu \mathrm{g}$ & 8 & 1 & & 5 & 3 & 6 & & & & & & \\
\hline $0.5 \mu \mathrm{g}$ & & 2 & & 4 & & & & & & & & \\
\hline
\end{tabular}

Ciprofloxacin (CIP), Gentamicin (GN), Vancomycin (VA), Amoxicillin/clavulanic acid (AMC), Cefotaxime (CXT), Imipenem (IMP).

Table 6. MICs for CONS planktonic and biofilm forming cells by the microbroth dilution method.

\begin{tabular}{cccccccccccccc}
\hline \multirow{2}{*}{$\begin{array}{c}\text { Antibiotic } \\
\text { conc/ml }\end{array}$} & \multicolumn{3}{c}{ Planktonic strains (total = 84) } & \multicolumn{7}{c}{ Biofilm strains (total = 84) } \\
\cline { 2 - 11 } & AMC & CXT & GN & IMP & VA & CIP & AMC & CXT & GN & IMP & VA & CIP \\
\hline $1024 \mu \mathrm{g}$ & & & & & & & 8 & 7 & 21 & 2 & 11 & 4 \\
$512 \mu \mathrm{g}$ & & & 2 & & & & 21 & 14 & 26 & 11 & 24 & 17 \\
$256 \mu \mathrm{g}$ & & & 3 & & 4 & & 16 & 17 & 30 & 15 & 18 & 15 \\
$128 \mu \mathrm{g}$ & & 1 & 8 & & 8 & 3 & 22 & 21 & 7 & 20 & 14 & 22 \\
$64 \mu \mathrm{g}$ & 2 & 21 & 22 & & 21 & 22 & 15 & 17 & & 17 & 13 & 12 \\
$32 \mu \mathrm{g}$ & 12 & 16 & 17 & & 23 & 17 & 2 & 8 & & 11 & 4 & 9 \\
$16 \mu \mathrm{g}$ & 23 & 12 & 20 & 7 & 15 & 13 & & & & 7 & & 5 \\
$8 \mu \mathrm{g}$ & 22 & 21 & 6 & 31 & 6 & 10 & & & & 1 & & \\
$4 \mu \mathrm{g}$ & 13 & 7 & 5 & 20 & 2 & 8 & & & & & & \\
$2 \mu \mathrm{g}$ & 9 & 4 & 1 & 21 & 3 & 9 & & & & & & \\
$1 \mu \mathrm{g}$ & 3 & 2 & & 4 & 2 & 2 & & & & & & \\
$0.5 \mu \mathrm{g}$ & & & & 1 & & & & & & & & \\
\hline
\end{tabular}

Ciprofloxacin (CIP), Gentamicin (GN), Vancomycin (VA), Amoxicillin/clavulanic acid (AMC), Cefotaxime (CXT), Imipenem (IMP).

for planktonic cells. The results agree with those obtained by the BTA method (Table 7 and Table 8). In addition, Table 7 and Table 8 show that the MICs for biofilm cells were higher than that for planktonic cells, as determined by the 


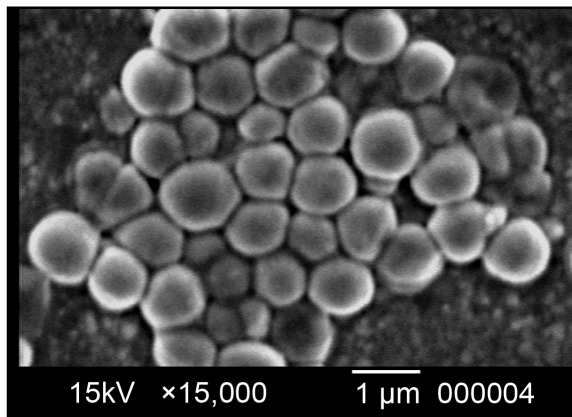

(a)

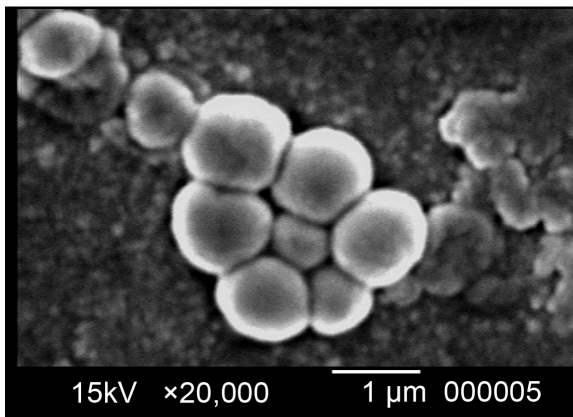

(b)

Figure 2. SEM image of biofilm-forming COPS.

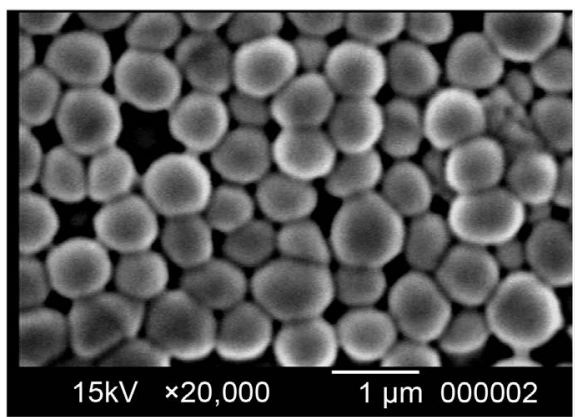

(a)

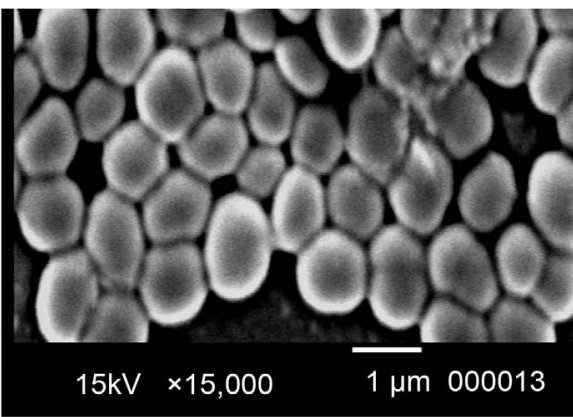

(b)

Figure 3. SEM image of biofilm-forming CONS.

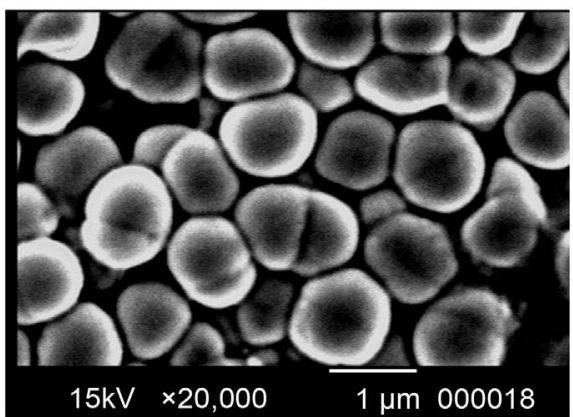

(a)

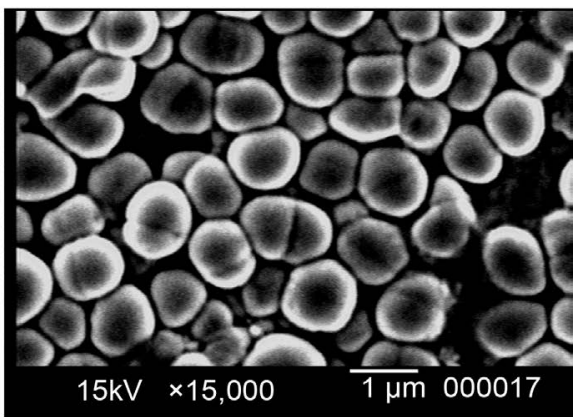

(b)

Figure 4. SEM image of biofilm-forming strains after overnight incubation with ciprofloxacin $(128 \mu \mathrm{g})$. (a) COPS; (b) CONS.

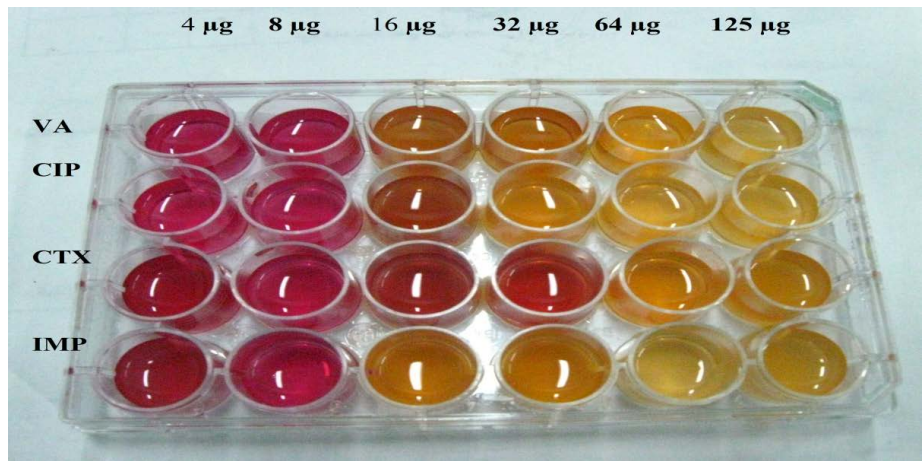

Figure 5. MICs of ciprofloxacin for biofilm forming cells of COPS by BTA method. 


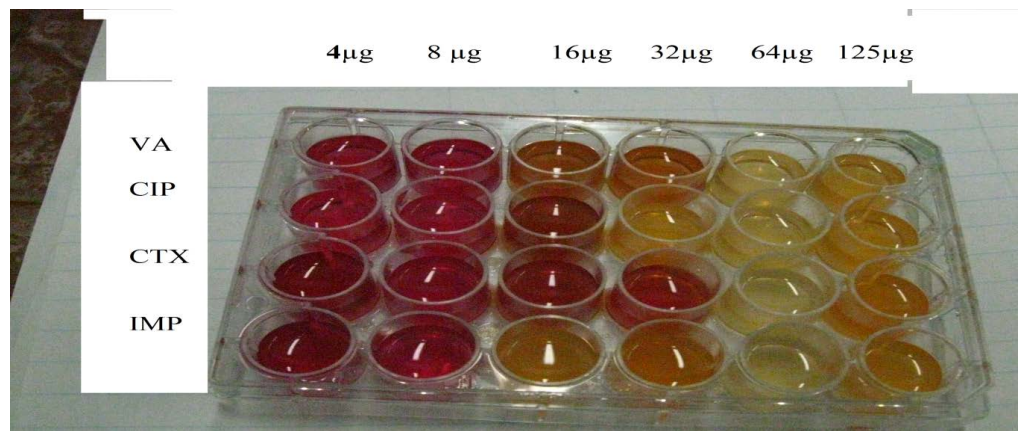

Figure 6. MICs for biofilm-forming cells of CONS by BTA method.

Table 7. MICs for COPS planktonic and biofilm forming cells by the BTA method.

\begin{tabular}{ccccccccccccc}
\hline \multirow{2}{*}{$\begin{array}{r}\text { Antibiotic } \\
\text { conc/ml }\end{array}$} & \multicolumn{3}{c}{ Planktonic strains (total=122) } & \multicolumn{5}{c}{ Biofilm strains (total=122) } \\
\cline { 2 - 11 } & AMC & CXT & GN & IMP & VA & CIP & AMC & CXT & GN & IMP & VA & CIP \\
\hline $1024 \mu \mathrm{g}$ & & & & & & & 7 & 5 & 25 & 2 & 16 & 4 \\
$512 \mu \mathrm{g}$ & & & 2 & & 3 & & 28 & 15 & 43 & 6 & 25 & 16 \\
$256 \mu \mathrm{g}$ & & & 6 & & 4 & & 33 & 21 & 40 & 15 & 32 & 26 \\
$128 \mu \mathrm{g}$ & 1 & 2 & 15 & & 7 & 4 & 32 & 32 & 13 & 24 & 26 & 30 \\
$64 \mu \mathrm{g}$ & 4 & 24 & 24 & 2 & 24 & 29 & 18 & 30 & 1 & 32 & 16 & 22 \\
$32 \mu \mathrm{g}$ & 15 & 23 & 31 & 5 & 34 & 18 & 4 & 15 & & 25 & 7 & 14 \\
$16 \mu \mathrm{g}$ & 27 & 17 & 25 & 16 & 20 & 15 & & 4 & & 12 & & 10 \\
$8 \mu \mathrm{g}$ & 29 & 29 & 12 & 32 & 13 & 13 & & & & 6 & & \\
$4 \mu \mathrm{g}$ & 24 & 16 & 6 & 28 & 10 & 16 & & & & & & \\
$2 \mu \mathrm{g}$ & 12 & 9 & 1 & 30 & 5 & 20 & & & & & & \\
$1 \mu \mathrm{g}$ & 10 & 1 & & 7 & 2 & 7 & & & & & & \\
$0.5 \mu \mathrm{g}$ & & 1 & & 2 & & & & & & & & \\
\hline
\end{tabular}

Ciprofloxacin (CIP), Gentamicin (GN), Vancomycin (VA), Amoxicillin/clavulanic acid (AMC), Cefotaxime (CXT), Imipenem (IMP).

Table 8. MICs for CONS planktonic and biofilm forming cells by the BTA method.

\begin{tabular}{ccccccccccccc}
\hline \multirow{2}{*}{$\begin{array}{c}\text { Antibiotic } \\
\text { conc/ml }\end{array}$} & \multicolumn{4}{c}{ Planktonic strains (total = 84) } & \multicolumn{5}{c}{ Biofilm strains (total= 84) } \\
\cline { 2 - 11 } & AMC & CXT & GN & IMP & VA & CIP & AMC & CXT & GN & IMP & VA & CIP \\
\hline $1024 \mu \mathrm{g}$ & & & 4 & & & & 6 & 8 & 24 & 1 & 14 & 3 \\
$512 \mu \mathrm{g}$ & & & 8 & & & & 21 & 18 & 22 & 10 & 21 & 15 \\
$256 \mu \mathrm{g}$ & & & 21 & & 7 & & 18 & 16 & 27 & 13 & 14 & 15 \\
$128 \mu \mathrm{g}$ & 3 & 1 & 23 & & 5 & 3 & 20 & 17 & 11 & 16 & 18 & 24 \\
$64 \mu \mathrm{g}$ & 22 & 4 & 15 & & 24 & 4 & 17 & 14 & & 21 & 11 & 13 \\
$32 \mu \mathrm{g}$ & 17 & 16 & 6 & 3 & 20 & 17 & 2 & 6 & & 8 & 6 & 8 \\
$16 \mu \mathrm{g}$ & 13 & 15 & 2 & 11 & 11 & 12 & & 5 & & 13 & & 6 \\
$8 \mu \mathrm{g}$ & 10 & 22 & 3 & 14 & 10 & 22 & & & & 2 & & \\
$4 \mu \mathrm{g}$ & 8 & 12 & 2 & 21 & & 12 & & & & & & \\
$2 \mu \mathrm{g}$ & 9 & 9 & & 18 & 5 & 9 & & & & & & \\
$1 \mu \mathrm{g}$ & 2 & 5 & & 13 & 2 & 5 & & & & & & \\
$0.5 \mu \mathrm{g}$ & & & & 4 & & & & & & & & \\
\hline
\end{tabular}

Ciprofloxacin (CIP), Gentamicin (GN), Vancomycin (VA), Amoxicillin/clavulanic acid (AMC), Cefotaxime (CXT), Imipenem (IMP). 
BTA method.

\section{Discussion}

The structural and physiological properties of biofilm-producing organisms confer an inherent resistance to antimicrobial agents [20]. Since rates of antibiotic resistance are currently increasing owing to biofilm production in staphylococci, more research is needed to overcome this problem. The current study was carried out on 260 Staphylococcal spp. (coagulase-positive, 155; coagulase-negative, 105) strains. Of the COPS, $78.7 \%(122 / 155)$ of strains were biofilm producers, while of the CONS, $80 \%(84 / 105)$ of strains were biofilm producers. Biofilm-forming COPS strains, as determined via the TCP method, were classified as strong $(51.6 \%, 80 / 155)$, moderate $(27.1 \%, 42 / 155)$, or weak/non-biofilm forming $(21.3 \%, 33 / 155)$. CONS strains were classified similarly, presenting $47.6 \%$ (50/105) strong, 32.4\% (34/105) moderate, and 20\% (21/105) weak/non-biofilm strains (Table 2).

Certain antibiotics were used to evaluate their effect on biofilm production by COPS and CONS strains. The results revealed that biofilm-producing bacteria were more resistant to antibiotics than non-biofilm-producing bacteria were (Table 4 and Table 5). The efficacies of these antibiotics were evaluated using a concentration range based on MIC. Antibiotics showed variable activity against COPS biofilms. For planktonic strains, imipenem (IMP) showed the greatest effect, causing a complete reduction of the bacterial strains at a concentration of $32 \mu \mathrm{g} / \mathrm{ml}$. AMC, CXT, and CIP caused a complete reduction at a concentration of $128 \mu \mathrm{g} / \mathrm{ml}$, while VA caused a complete reduction at $512 \mu \mathrm{g} / \mathrm{ml}$, and finally GN caused a complete reduction at $1024 \mu \mathrm{g} / \mathrm{ml}$. Regarding biofilm strains, at a concentration of $512 \mu \mathrm{g} / \mathrm{ml}$, IMP gave the highest effect, causing reduction in 97.5\% (119/122) of strains. Ciprofloxacin caused reduction in 95.1\% (116/122) of strains at the same concentration, and CXT, AMC, VA, and GN caused reduction in $93.4 \%$ (114/122), 90.9\% (111/122), 86.8\% (106/122), and 76.2\% (93/122) of strains (Table 5 ).

These results agree with those obtained by Tote et al. [21] and Mathur et al. [22]. They reported that $S$. epidermidis was able to produce biofilms and cause implant infections. The resistance of 342 clinical strains of $S$. epidermidis from orthopedic implant infections to 16 different antibiotics has been investigated previously. The isolates were phenotyped and genotyped for extracellular polysaccharide production relevant to staphylococcal biofilm formation in order to ascertain possible associations with antibiotic resistance. Approximately $10 \%$ of the isolates were found to be sensitive to all screened antibiotics. In all, 37\% $38 \%$ of strains were resistant to $\beta$-lactams such as oxacillin and imipenem, while resistance to penicillin, ampicillin, cefazolin, and cefamandole was observed consistently in over $80 \%$ of strains. About $41 \%$ and $16 \%$ of erythromycin- and clindamycin-resistant strains, respectively, were noted. Of the isolates, $10 \%$ were resistant to chloramphenicol, $23 \%$ to sulfamethoxazole, and $26 \%$ to ciprofloxacin. Resistance to vancomycin was never observed. Exopolysaccharide-producing 
strains exhibited a higher prevalence of resistance to the four aminoglycosides (gentamicin, amikacin, netilmicin, and tobramycin), sulfamethoxazole, and ciprofloxacin relative to non-producing isolates. Resistance to multiple antibiotics was more common among exopolysaccharide-forming strains.

Amorena et al. [23] reported that antibiotic susceptibility identification using the microbroth dilution method was similar when comparing suspensions of SP (slime producing) versus NSP (non-slime producing) variants of $S$. aureus isolates. The observation that antibiotic potency was $100 \%$ in the microbroth dilution tests at $1 \times \mathrm{MBC}$ but did not reach $1 \times \log _{10} \mathrm{CFU}$ when antibiotics were used at $4 \times \mathrm{MBC}$ against young $(6 \mathrm{~h})$ TSB-grown biofilms may represent a warning signal concerning the exclusive use of classical in vitro tests. Singh et al. [24] found that the penetration of oxacillin, cefotaxime ( $\beta$-lactams), and vancomycin (a glycopeptide) through $S$. aureus and $S$. epidermidis biofilms significantly decreased, whereas that of amikacin (an aminoglycoside) and ciprofloxacin (a fluoroquinolone) was unaffected. The in vitro killing effect of the widely used antibiotics (cephalothin, clindamycin, erythromycin, ofloxacin, rifampicin, teicoplanin, tetracycline, phosphomycin, and vancomycin) was comparatively analyzed previously by Oteiza [25], on 24-h biofilms of 64 S. epidermidis clinical isolates. This effect was assessed at the expected antibiotic concentration reached in serum using ATP-bioluminescence. Erythromycin, rifampicin, tetracycline, and phosphomycin generally presented a higher killing effect than vancomycin, clindamycin, cephalothin, teicoplanin, and ofloxacin. Differences in the resistance profiles obtained in classical assays (broth microdilution and diffusion) did not help to predict differences in antibiotic killing potency in biofilms. Antibiotic killing potency decreased as biofilm age increased (from 6 to 24 or $48 \mathrm{~h}$ ) for some antibiotics such as vancomycin, but that of rifampicin or tetracycline was not affected. Berlutti et al. [26] presented an improved method called the BioTimer assay, which can be successfully applied to directly enumerate Staphylococcus in biofilms without any sample manipulation. The BTA method can be used to count Staphylococcus via a genus-specific correlation line that correlates the time required for BT-PR medium color switch with the initial concentration of planktonic bacteria. To validate the BTA method, BTA results, both in counting and in evaluating MICs of planktonic Staphylococcus, have been compared to those obtained by reference methods.

Pantanella et al. [19] reported, using the BTA method, viable Staphylococcus in biofilms in the presence of sub-inhibitory antibiotic concentrations. This observation agrees with our results, indicating the close agreement between BTA and microbroth methods for planktonic cell MIC values. The antibiotic effects on COPS (as determined by the BTA method) showed that imipenem had the greatest effect on COPS planktonic cells, causing $100 \%$ reduction at a concentration of $128 \mu \mathrm{g} / \mathrm{ml}$. However, reduction decreased to $98.3 \%$ at $64 \mu \mathrm{g} / \mathrm{ml}, 94.2 \%$ at $32 \mu \mathrm{g} / \mathrm{ml}$, and $81.1 \%$ at $16 \mu \mathrm{g} / \mathrm{ml}$, leaving $18.9 \%$ of the cells for facilitation of re-colonization at that concentration. Ciprofloxacin caused a $100 \%$ reduction at a concentration of $256 \mu \mathrm{g} / \mathrm{ml}$. However, reduction decreased to $97.5 \%$ at $128 \mu \mathrm{g}$ 
and $72.9 \%$ at $56 \mu \mathrm{g} / \mathrm{ml}$, leaving $27.1 \%$ of the cells for re-colonization. Gentamicin eradicated $81.1 \%$ of the planktonic cells at a concentration of $128 \mu \mathrm{g} / \mathrm{ml}$, and was the least active. We therefore concluded that at the same antibiotic concentration, the eradication of planktonic cells was much higher than that of biofilm cells. In other words, for a certain antibiotic, the concentration required for complete eradication of biofilm strains is much higher than that required for planktonic cells. These results agree with those obtained by the BTA method (Table 7 and Table 8), which also show that MICs of biofilm cells were higher than that of planktonic cells.

The effect of antibiotics on CONS strains showed that imipenem had the greatest effect on biofilm formation, causing an $87 \%$ reduction of the biofilm at a concentration of $256 \mu \mathrm{g} / \mathrm{ml}$ by the microtube dilution method and $84.5 \%$ reduction by the BTA method. Therefore, the MIC required, for any antibiotic, for the eradication of biofilm cells is much higher than that required for non-biofilm cells. The BTA method has been proven to be reliable.

\section{Acknowledgements}

The authors extend their appreciation to the College of Pharmacy Research Center, Deanship of Scientific Research at King Saud University for funding this work.

\section{Conflict of Interests}

The authors declare that there is no conflict of interests regarding the publication of this paper.

\section{References}

[1] Jessica, L. and Horswill, L. (2014) Staphylococcus aureus Biofilms: Recent Developments in Biofilm Dispersal. Frontiers in Cellular and Infection Microbiology, 4 , 178.

[2] Lewis, K. (2001) Riddle of Biofilm Resistance. Antimicrobial Agents and Chemotherapy, 45, 999-1007. https://doi.org/10.1128/AAC.45.4.999-1007.2001

[3] Herrera, J.J.R., Cabo, M.L., González, A., Pazos, I. and Pastoriza, L. (2007) Adhesion and Detachment Kinetics of Several Strains of Staphylococcus aureus subsp. aureus under Three Different Experimental Conditions. Food Microbiology, 24, 585-591. https://doi.org/10.1016/j.fm.2007.01.001

[4] Foulston, L., Elsholz, A.K., Defrancesco, A.S. and Losick, R. (2014) The Extracellular Matrix of Staphylococcus aureus Biofilms Comprises Cytoplasmic Proteins That Associate with the Cell Surface in Response to Decreasing pH. MBio, 5, e01667e01614. https://doi.org/10.1128/mBio.01667-14

[5] Oliveira, A. and Cunha, M.L.R.S. (2010) Comparison of Methods for the Detection of Biofilm Production in Coagulase-Negative Staphylococci. BMC Research Notes, 3, 260. https://doi.org/10.1186/1756-0500-3-260

[6] Lira, M.C., Givisiez, P.E., De Sousa, F.G., Magnani, M., De Souza, E.L., Spricigo, D.A., Gebreyes, W.A. and De Oliveira, C.J. (2016) Biofilm-Forming and Antimicrobial Resistance Traits of Staphylococci Isolated from Goat Dairy Plants. Journal of Infection in Developing Countries, 10, 932-938. 
[7] Feuillie, C., Formosa-Dague, C., Hays, L.M., Vervaeck, O., Derclaye, S., Brennan, M.P., Foster, T.J., Geoghegan, J.A. and Dufrêne, Y.F. (2017) Molecular Interactions and Inhibition of the Staphylococcal Biofilm-Forming Protein SdrC. Proceedings of the National Academy of Sciences of the United States of America, 114, 3738-3743. https://doi.org/10.1073/pnas.1616805114

[8] Foster, T.J., Geoghegan, J.A., Ganesh, V.K. and Hook, M. (2014) Adhesion, Invasion and Evasion: The Many Functions of the Surface Proteins of Staphylococcus aureus. Nature Reviews Microbiology, 12, 49-62.

https://doi.org/10.1038/nrmicro3161

[9] Tony, R. (2008) Entrapment within the Biofilm Environment Limits Bacterial Growth Ultrastructural Organization of a Biomaterial Adhesion of Staphylococcus epidermidis. Journal of Bacteriology, 178, 537-541.

[10] Hoiby, N., Frederiksen, B. and Pressler, T. (2005) Eradication of Early Pseudomonas aeruginosa Infection. Journal of Cystic Fibrosis, 4, 49-54.

https://doi.org/10.1016/j.jcf.2005.05.018

[11] Ansari, M.A., Khan, H.M., Khan, A.A., Cameotr, S.S. and Alzohairy, M.A. (2015) Anti-Biofilm Efficacy of Silver Nanoparticles against MRSA and MRSE Isolated from Wounds in a Tertiary Care Hospital. Indian Journal of Medical Microbiology, 33, 101-109.

[12] Masurkar, S.A., Chaudhari, P.R., Shidore, V.B. and Kamble, S.P. (2012) Effect of Biologically Synthesized Silver Nanoparticles on Staphylococcus aureus Biofilm Quenching and Prevention of Biofilm Formation. Nanobiotechnology, 6, 110-114. https://doi.org/10.1049/iet-nbt.2011.0061

[13] Ansari, M.A., Khan, H.M., Khan, A.A., Cameotra, S.S., Saquib, Q. and Musarrat, J. (2014) Gum Arabic Capped-Silver Nanoparticles Inhibit Biofilm Formation by Multi-Drug Resistant Strains of Pseudomonas aeruginosa. Journal of Basic Microbiology, 54, 688-699. https://doi.org/10.1002/jobm.201300748

[14] Collee, J.G., Fraser, A.G., Marmion, B.P. and Simmons, A. (1996) Tests for Identification of Bacteria. In: Mackie \& McCartney Practical Medial Microbiology, 14th Edition, Churchill Livingstone Inc., New York, 131-149.

[15] Kloos, W.E. and Wolfshohl, J.F. (1982) Identification of Staphylococcus Species with the API STAPH-IDENT System. Journal of Clinical Microbiology, 16, 509-516.

[16] Christensen, G.D., Simpson, W.A., Younger, J.A., Baddour, L.M., Barrett, F.F., Melton, D.M., et al. (1985) Adherence of Cogulase Negative Staphylococi to Plastic Tissue Cultures: A Quantitative Model for the Adherence of Staphylococci to Medical Devices. Journal of Clinical Microbiology, 22, 996-1006.

[17] Stepanovic, S., Vukovi, D., Hola, V., Di Bonaventura, G., Djukić, S., Cirković, I. and Ruzicka, F. (2007) Quantification of Biofilm in Microtiter Plates: Overview of Testing Conditions and Practical Recommendations for Assessment of Biofilm Production by Staphylococci. APMIS, 115, 891-899.

https://doi.org/10.1111/j.1600-0463.2007.apm_630.x

[18] Clinical and Laboratory Standards Institute (CLSI) (2015) Performance Standards for Antimicrobial Testing. 25th Informational Supplement, Clinical and Laboratory Standards Institute, Wayne, PA.

[19] Pantanella, F., Valenti, P., Frioni, A., Natalizi, T., Coltella, L. and Berlutti, F. (2008) BioTimer Assay, a New Method for Counting Staphylococcus spp. in Biofilm without Sample Manipulation Applied to Evaluate Antibiotic Susceptibility of Biofilm. Journal of Microbiological Methods, 75, 478-484. https://doi.org/10.1016/j.mimet.2008.07.027

[20] Reffuveille, F., de la Fuente-Nunez, C., Mansour, S. and Hancock, R.E. (2014) A 
Broad-Spectrum Antibiofilm Peptide Enhances Antibiotic Action against Bacterial Biofilms. Antimicrobial Agents and Chemotherapy, 58, 5363-5371. https://doi.org/10.1128/AAC.03163-14

[21] Tote, K., Horemans, T. and Cos, P. (2009) Antibiotic Resistance of Bacterial Biofilms. Journal of Microbiological Methods, 60, 288-295.

[22] Mathur, T., Singhal, S., Khan, S., Upadhyay, D.J., Fatma, T. and Rattan, A. (2006) Detection of Biofilm Formation among the Clinical Isolates of Staphylococci: An Evaluation of Three Different Screening Methods. Indian Journal of Medical Microbiology, 24, 25-29. https://doi.org/10.4103/0255-0857.19890

[23] Amorena, B., Gracia, E. and Monzon, M. (1999) Antibiotic Susceptibility Assay for Staphylococcus aureus in Biofilms Developed in Vitro. Journal of Antimicrobial Chemotherapy, 44, 43-55. https://doi.org/10.1093/jac/44.1.43

[24] Singh, R., Pallab, R. and Anindita, D. (2005) Role of Persisters and Small-Colony Variants in Antibiotic Resistance of Planktonic and Biofilm-Associated Staphylococcus aureus: An in Vitro Study. Journal of Medical Microbiology, 58, 1067-1073. https://doi.org/10.1099/jmm.0.009720-0

[25] Oteiza (2003) Biofilm Eradication and Prevention. Journal of Food Safety, 63, 340 345.

[26] Berlutti, F., Rosso, F. and Bosso, P. (2003) Quantitative Evaluation of Bacteria Adherent to Polyelectrolyte Hema-Based Hydrogels. Journal of Biomedical Materials Research, 67A, 18-25. https://doi.org/10.1002/jbm.a.10026

Submit or recommend next manuscript to SCIRP and we will provide best service for you:

Accepting pre-submission inquiries through Email, Facebook, LinkedIn, Twitter, etc. A wide selection of journals (inclusive of 9 subjects, more than 200 journals)

Providing 24-hour high-quality service

User-friendly online submission system

Fair and swift peer-review system

Efficient typesetting and proofreading procedure

Display of the result of downloads and visits, as well as the number of cited articles

Maximum dissemination of your research work

Submit your manuscript at: http://papersubmission.scirp.org/

Or contact aim@scirp.org 